\title{
Overview of OPAMP and OTA based Integrators
}

\author{
Dattaguru V. Kamath \\ Dept. of E\&C Engg., Manipal Institute of Technology, Manipal University, Manipal, India \\ E-mail:dv.kamath@manipal.edu
}

\begin{abstract}
The circuit realization of lossless and lossy integrators using active devices like opamp and OTA have been discussed. The realization of integrator in single ended and fully differential configurations is considered. The voltagemode and current-mode integrators reported in the literature have been considered. The realization of OTA-based transadmittance type integrator has been considered. The OTA based integrator circuits have been simulated in PSPICE using a behavioral macro-model of the OTA as well with a practical CMOS OTA circuit. The amplitude and phase response plots obtained for OTA based integrators are presented.
\end{abstract}

Keywords: Opamp; Operational Transconductance Amplifier (OTA); Lossless and lossy integrator; Voltage-mode and current-mode integrator

\section{INTRODUCTION}

Continuous-time (CT) or analog filters [1]-[20] are the most important analogue blocks in integrated signalprocessing systems, especially in applications where the filters interface with the outside world. In the recent years, the use of continuous-time filters using active devices like opamp, operational transconductance amplifier (OTA) and current feedback operational amplifier (CFOA) has drawn more interest.

Integrators, summer/ subtractor (summing or difference amplifier) and scaling amplifiers are the important building blocks used in the design of continuous-time filters. The integrators are the important building blocks used in the design of continuous-time filter structures. There are two types of integrators i.e., ideal or lossless and lossy integrator. The ideal or lossless integrators alone are used in CT filter structures like Kerwin-Huelsman-Newcomb (KHN) biquad [1], [2], [5][8], two-integrator loop feedback configuration [1]-[3], [5]-[7], multiple integrator loop feedback (MILF) configuration [1]-[2], [5]-[7]. The two-integrator loop filters are a very popular category for second-order filter realization, as they offer low sensitivity to component values and permit realization of several transfer functions. Both lossless and lossy integrators are used in CT filter structures like Tow-Thomas biquad [1], [2], [5]-[7], [9][10], Akerberg-Mossberg biquad [1], [2], [5]-[7], [11].

Several different approaches are developed over years for synthesis of analog filter structures. The active-RC filters [1], [2], [5] - [7] largely superseded the classical LCR filters in the low and medium frequency range with the availability of op-amp. Most of the active-RC filter circuits use typical opamp-RC integrators to realize firstorder and second-order (biquad) sections. These first-order and second-order sections are cascaded to design highorder filters. The different types of opamp based active$\mathrm{RC}$ integrators are discussed in section II.

The Opamp-MOSFET-C filters [2], [5] use MOSFET as a voltage controlled resistor biased in the ohmic region, with the resistance being adjustable by the gate bias voltage. Thus, the MOSFET-C filters can be constructed by replacing resistors in active-RC filters by their corresponding MOSFET. This approach is affected by inherent nonlinearity of the MOS transistors that must be cancelled. The fully differential Opamp-MOSFET-C filter circuits are described in literature [12] which can remove the even-order non-linear distortion. The MOSFET-C filters, however, need complicated frequency control tuning loops to adjust the critical frequencies of the filters by dynamically changing the resistance of the MOS transistors. These do not, however, exhibit the excellent linearity of the active-RC filters. The Opamp-MOSFET-C integrators are discussed in section III

In OTA-C-Opamp filters [4], [5] the resistor used in opamp-RC filters is replaced by an OTA. These filters are not affected by the parasitic capacitance that is present at the output terminal of the OTAs. However, these filters consume more power than active-RC filters. The OTA-COpamp integrators are presented in section IV.

In active $\mathrm{R}$ filters [13]-[15] the opamp is considered as an integrator. Hence, using two such integrators and only resistors, second-order active filters are constructed. The pole-Qs of active $\mathrm{R}$ biquads are dependent on resistor ratios and/ or ratios of bandwidths of two opamps. The pole-frequency, on the other hand, is dependent on the absolute values of bandwidths of opamps and resistor ratios. The demerit is that the pole-frequency is dependent on the actual bandwidth of the opamp, which usually is affected by power supply voltage and temperature.

Currently, the continuous-time (CT) filter designs use devices other than op-amps such as OTAs. The two attractive features of OTA are the controllability of transconductance by changing the dc bias current and the ability to work at higher frequencies. It is shown that the grounded and floating type resistors [2]-[7] can be simulated using OTAs. The grounded and floating inductances can be realized using OTAs and one grounded capacitor [2]-[7]. By replacing resistors and inductors with the simulated OTA circuits, the fully integrable and fully programmable high-frequency active filters that use only OTAs and capacitors are realized.

The OTA-C approach, where in only OTAs and capacitors are used, is shown to be useful for realizing 
voltage-mode [3]-[7] and current-mode [4]-[7], [16]-[27] filters. From last two decades, there is growing interest in Current-Mode Signal Processing (CMSP) because of its advantages like increased band-width and reduced power supply requirements. The single output OTAs (SO-OTA) are popularly used for realizing voltage-mode filters. The dual output OTAs (DO-OTA) are employed to realize the current-mode active filters having current-input currentoutput (CICO) transfer functions. Both transimpedance/ transadmittance OTA-C filters [29], [30] are considered in literature. The voltage-mode, current-mode and transadmittance type OTA-based integrators are discussed in section $\mathrm{V}$.

The transconductor and transresistor circuits are used during voltage-to-current or current-to-voltage interfacing, during which it is also possible to perform signal processing (like integrator) at the same time, so that the circuit performance is enhanced. The OTA based transadmittance type filters are reported, which act as interface filter circuits connecting voltage-mode circuits and current-mode circuits. One of the most important application areas of the transadmittance filters are in the receiver baseband $(\mathrm{BB})$ blocks of modern radio systems.

The active-RC integrator using feed forward compensated op-amp is discussed in section VI.

The PSPICE simulation results of OTA based integrator circuits obtained using a behavioral macromodel of the OTA as well with a practical CMOS OTA circuit are presented in section VII. The concluding remarks are given in section VIII.

\section{ACTIVE-RC INTEGRATORS}

\section{A. Inverting type integrator}

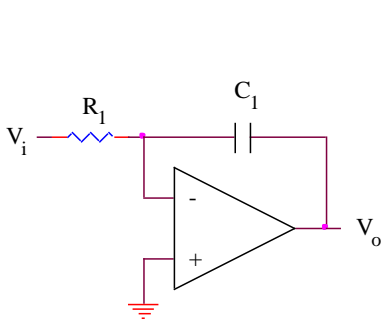

(a)

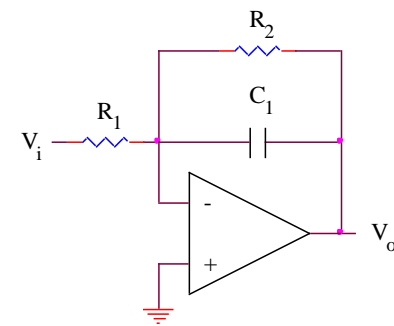

(b)
Fig. 1 Single ended inverting type op-amp based voltage-mode integrators (a) lossless (b) lossy

The single ended inverting type opamp based voltagemode lossless and lossy integrators are shown in Fig. 1 (a)-(b), the transfer function of which are shown to be

$$
\begin{gathered}
\frac{V_{o}}{V_{i}}=-\frac{1}{s R_{1} C_{1}} \\
\frac{V_{o}}{V_{i}}=-\frac{R_{2}}{R_{1}} \frac{1}{\left(1+s R_{2} C_{1}\right)}
\end{gathered}
$$

The circuit in Fig. 1(a) is also called as Miller integrator because the capacitor is used in the feedback path. The pole-frequency or unity-gain frequency of the op-amp based Miller integrator in Fig. 1(a) is given by

$$
\omega_{0}=\frac{1}{\mathrm{R}_{1} \mathrm{C}_{1}}
$$

The dc gain and pole-frequency of the opamp based lossy integrator in Fig. 1(b) are shown to be

$$
\begin{gathered}
\frac{V_{o}}{V_{i}}(j 0)=-\frac{R_{2}}{R_{1}} \\
\omega_{0}=\frac{1}{R_{2} C_{1}}
\end{gathered}
$$

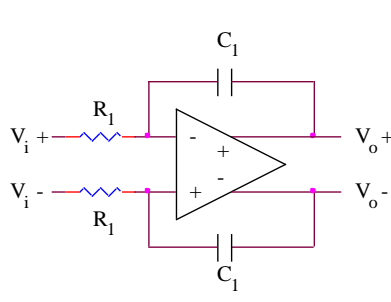

(a)

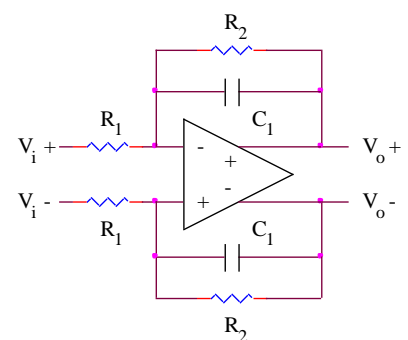

(b)
Fig. 2 Fully differential inverting type op-amp based voltage-mode integrators (a) lossless (b) lossy

The transfer function of fully differential opamp based voltage-mode lossless and lossy integrators in Fig. 2(a)-(b) are shown to be

$$
\begin{gathered}
\frac{\mathrm{V}_{\mathrm{o}}^{+}-\mathrm{V}_{\mathrm{o}}^{-}}{\mathrm{V}_{\mathrm{i}}^{+}-\mathrm{V}_{\mathrm{i}}^{-}}=-\frac{1}{\mathrm{sR}_{1} \mathrm{C}_{1}} \\
\frac{\mathrm{V}_{\mathrm{o}}^{+}-\mathrm{V}_{\mathrm{o}}^{-}}{\mathrm{V}_{\mathrm{i}}^{+}-\mathrm{V}_{\mathrm{i}}^{-}}=-\frac{\mathrm{R}_{2}}{\mathrm{R}_{1}} \frac{1}{\left(1+s \mathrm{R}_{2} \mathrm{C}_{1}\right)}
\end{gathered}
$$

\section{B. Non-inverting type integrator}

Due to negative sign in (1.1a), the opamp based Miller integrator is also said to be an inverting integrator. The non-inverting integrator can be obtained by connecting the output of Miller integrator to unity gain inverting amplifier as shown in Fig. 3.

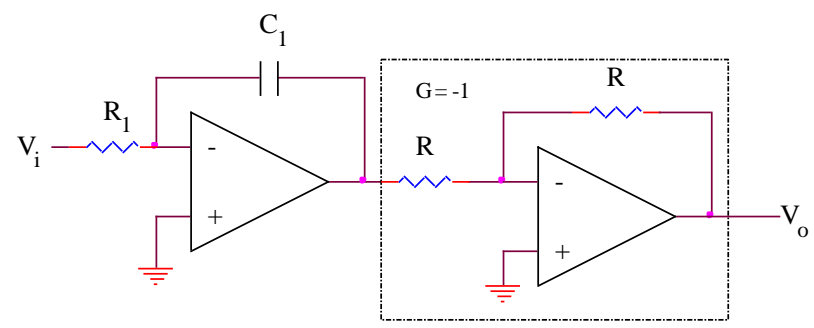

Fig. 3 Opamp based non-inverting integrator realized by cascading

Miller integrator and unity gain inverting amplifier.

The Deboo integrator is one of the popularly used noninverting type integrators. The conceptual implementation of non-inverting type Deboo integrator using passive components is shown in Fig. 4 (a). The opamp based negative impedance circuit is shown in Fig. 4 (b). 


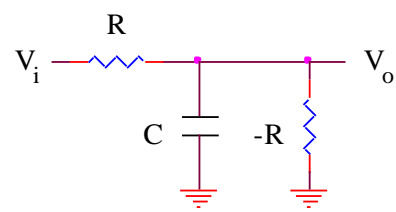

(a)

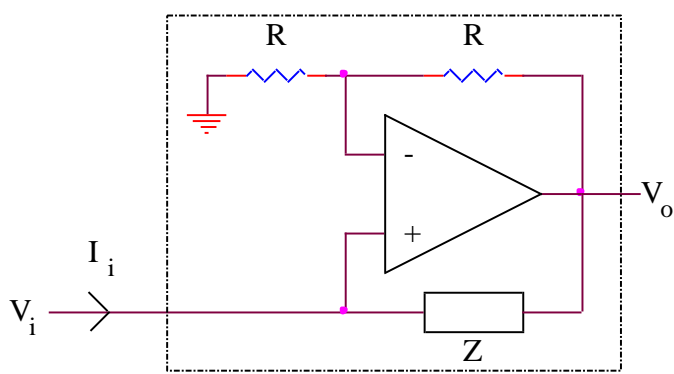

(b)

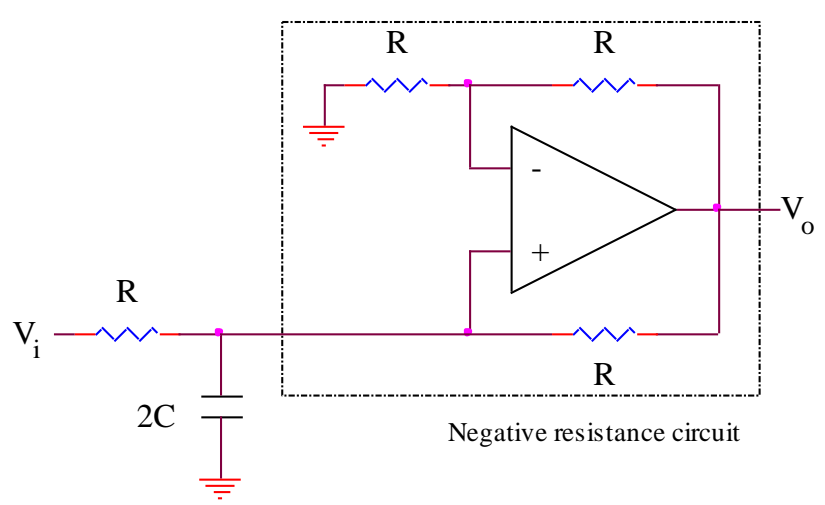

(c)

Fig. 4 (a) Conceptual implementation of non-inverting type integrator (b) Opamp based negative impedance circuit (c) Opamp based Deboo integrator

The opamp based Deboo integrator is shown in Fig. 4 (c). The Deboo circuit consists of three parts: the input resistor, the integrating capacitor, and the rest of the circuit - which is equivalent to a negative resistor connected to ground. By routine analysis, the transfer function of Deboo integrator is shown to be

$$
\frac{\mathrm{V}_{\mathrm{o}}}{\mathrm{V}_{\mathrm{i}}}=\frac{1}{\mathrm{sRC}}
$$

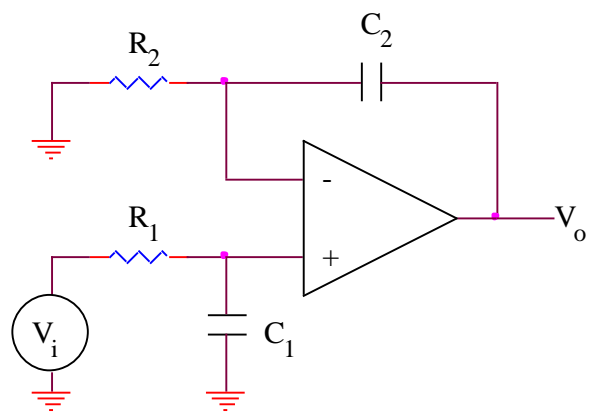

Fig. 5 An alternate type of opamp based non-inverting integrator
An alternate type of opamp based non-inverting integrator is shown in Fig. 5, the transfer function of which is shown to be

$$
\frac{\mathrm{V}_{\mathrm{o}}}{\mathrm{V}_{\mathrm{i}}}=\frac{1}{\mathrm{sR}_{2} \mathrm{C}_{2}} \frac{\left(1+\mathrm{sR} \mathrm{R}_{2} \mathrm{C}_{2}\right)}{\left(1+s \mathrm{R}_{1} \mathrm{C}_{1}\right)}
$$

From (2.1b), it follows that under the condition $\mathrm{R}_{1} \mathrm{C}_{1}=\mathrm{R}_{2} \mathrm{C}_{2}$ the circuit acts as a non-inverting integrator.

\section{OPAMP-MOSFET-C INTEGRATORS}

The Opamp-MOSFET-C ideal integrator in a single ended configuration is shown in Fig. 6, the transfer function of which is shown to be

$$
\frac{\mathrm{V}_{\mathrm{o}}}{\mathrm{V}_{\mathrm{in}}}=-\frac{1}{\mathrm{sr}_{\mathrm{ds}} \mathrm{C}}
$$

Here MOSFET is biased in ohmic region and is used as a voltage controlled resistor, the resistance of which is shown to be

$$
\mathrm{r}_{\mathrm{ds}}=1 /\left\{\beta_{\mathrm{n}}\left(\mathrm{V}_{\mathrm{c}}-\mathrm{V}_{\mathrm{th}}-\mathrm{V}_{\mathrm{i}}\right)\right\}
$$

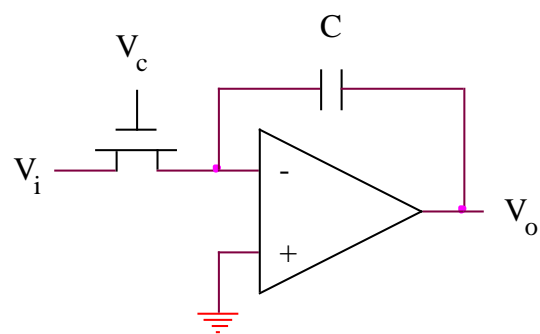

Fig. 6 Opamp-MOSFET-C ideal single ended integrator

\section{OTA-C-OPAMP INTEGRATORS}

The single ended OTA-C-Opamp ideal integrator circuit is shown in Fig. 7, the transfer function of which is shown to be

$$
\frac{\mathrm{V}_{\mathrm{o}}}{\mathrm{V}_{\mathrm{in}}}=-\frac{\mathrm{g}_{\mathrm{m}}}{\mathrm{sC}}
$$

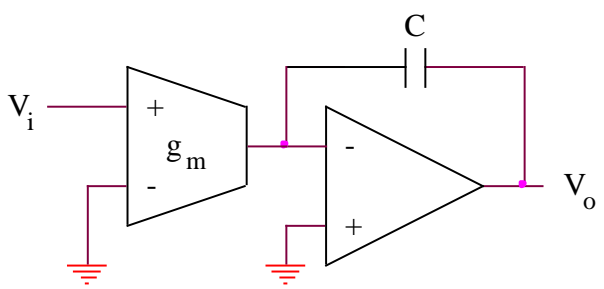

Fig. 7 OTA-C-Opamp single ended integrator

The OTA-C-Opamp integrator consists of an OTA and an opamp with a feedback capacitor. Here the OTA is used as a voltage-to- current converter.

\section{OTA BASED INTEGRATORS}

An ideal OTA is a differential-input voltage-controlled current source (VCCS), with infinite input and output 
impedances and a tunable transconductance. The symbols of SO-OTA (single-output OTA), DO-OTA (dual-output OTA) and MO-OTA (multiple-output OTA) are presented in Fig. 8. The output current of DO-OTA is given by

$$
\mathrm{I}_{\mathrm{o}}^{+}=\mathrm{I}_{\mathrm{o}}^{-}=\mathrm{g}_{\mathrm{m}}\left(\mathrm{V}_{\mathrm{i}}^{+}-\mathrm{V}_{\mathrm{i}}^{-}\right)
$$

where $\mathrm{I}_{0}^{+}, \mathrm{I}_{0}^{-}$are dual output currents, $\mathrm{g}_{\mathrm{m}}$ is the transconductance of the OTA, $\mathrm{V}_{i}^{+}$and $\mathrm{V}_{i}^{-}$denote noninverting and inverting input voltages of the DO-OTA respectively.

The two attractive features of OTA are (a) controllability of transconductance by changing the dc bias current and (b) ability to work at higher frequencies.

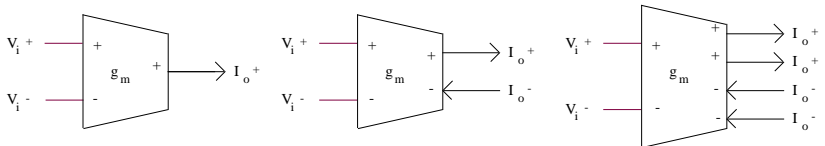

Fig. 8 Circuit symbol of SO-OTA, DO-OTA and MO-OTA

\section{A. OTA-C voltage-mode integrators}

The single ended inverting type OTA-C voltage-mode lossless integrator is shown in Fig. 9 (a), the transfer function of which is shown to be

$$
\frac{V_{o}}{V_{i}}=-\frac{g_{m 1}}{s C}
$$

The pole-frequency or unity-gain frequency of the ideal integrator in Fig. 9 (a) is

$$
\omega_{0}=\frac{g_{\mathrm{m} 1}}{\mathrm{C}}
$$

Connecting OTA simulated resistor of value $1 / \mathrm{g}_{\mathrm{m} 2}$ across capacitor $\mathrm{C}$, we get an OTA-C voltage-mode lossy integrator in Fig. 9 (b), the transfer function of which is shown to be

$$
\frac{V_{o}}{V_{i}}=-\frac{g_{m 1}}{\left(g_{m 2}+s C\right)}
$$

The dc gain and pole-frequency of the lossy integrator in Fig. 9 (b) are shown to be

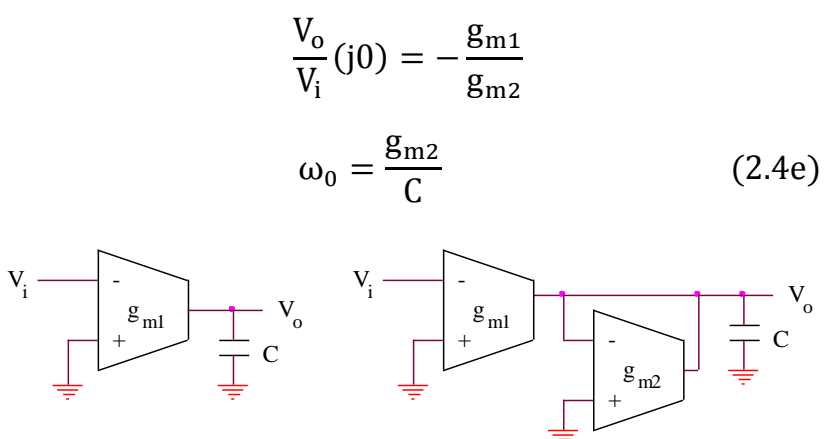

(a) (b)

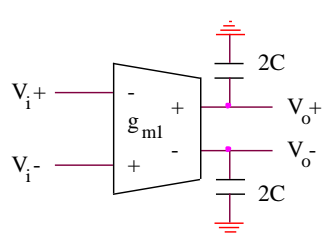

(a)

)

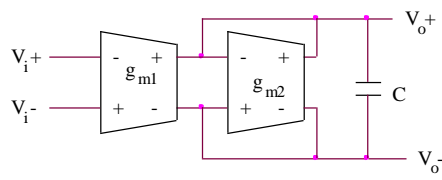

(b)
Fig. 10 Fully differential inverting type OTA-C voltage-mode integrators using floating capacitors (a) lossless (b) lossy (b)

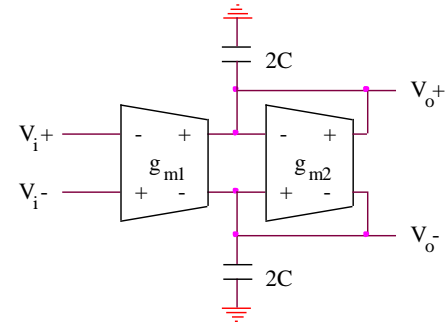

Fig. 11 Fully differential inverting type OTA-C voltage-mode integrators using grounded capacitors (a) lossless (b) lossy

The transfer function of fully differential OTA-C voltage-mode lossless and lossy integrators in Fig. 10 (a)(b) and Fig. 11 (a)-(b) are shown to be

$$
\begin{aligned}
& \frac{\mathrm{V}_{\mathrm{o}}^{+}-\mathrm{V}_{\mathrm{o}}^{-}}{\mathrm{V}_{\mathrm{i}}^{+}-\mathrm{V}_{\mathrm{i}}^{-}}=-\frac{\mathrm{g}_{\mathrm{m} 1}}{\mathrm{sC}} \\
& \frac{\mathrm{V}_{\mathrm{o}}^{+}-\mathrm{V}_{\mathrm{o}}^{-}}{\mathrm{V}_{\mathrm{i}}^{+}-\mathrm{V}_{\mathrm{i}}^{-}}=-\frac{\mathrm{g}_{\mathrm{m} 1}}{\left(\mathrm{~g}_{\mathrm{m} 2}+\mathrm{sC}\right)}
\end{aligned}
$$

\section{B. OTA-C current-mode integrators}

The single ended inverting type OTA-C current-mode lossless and lossy integrators are shown in Fig. 12 (a)-(b), the transfer function of which are respectively shown to be

$$
\begin{gathered}
\frac{\mathrm{I}_{\mathrm{o}}}{\mathrm{I}_{\mathrm{i}}}=-\frac{\mathrm{g}_{\mathrm{m} 1}}{\mathrm{sC}} \\
\frac{\mathrm{I}_{\mathrm{o}}}{\mathrm{I}_{\mathrm{i}}}=-\frac{\mathrm{g}_{\mathrm{m} 1}}{\left(\mathrm{~g}_{\mathrm{m} 2}+\mathrm{sC}\right)}
\end{gathered}
$$

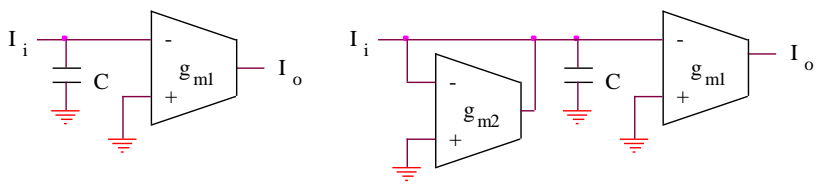

(a)

(b)

Fig. 12 Single ended inverting type OTA-C current-mode integrators (a) lossless (b) lossy 


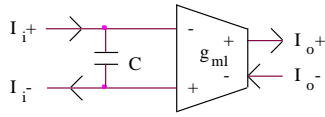

(a) (b)

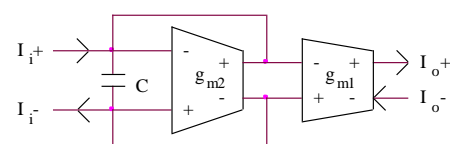

Fig. 13 Fully differential inverting type OTA-C current-mode integrators using floating capacitors (a) lossless (b) lossy

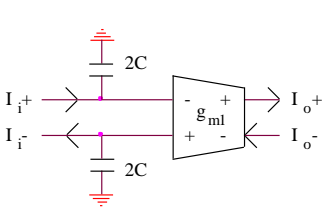

(a)

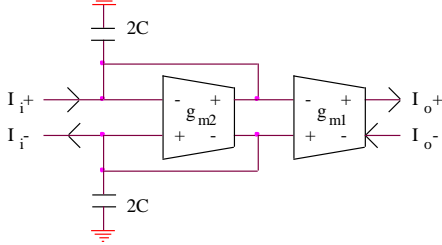

(b)
Fig. 14 Fully differential inverting type OTA-C current-mode integrators using grounded capacitors (a) lossless (b) lossy

The fully differential inverting type OTA-C currentmode lossless and lossy integrators using floating/ grounded capacitors are shown in Fig. 13 (a)-(b) and Fig. 14 (a)-(b) respectively.

\section{OTA-C transadmittance type integrators}

The lossless and lossy OTA-C transadmittance-mode integrators shown in Fig. 15 (a)-(b) are obtained from voltage-mode integrator circuits using an additional OTA to convert output voltage to current. The single ended lossy OTA-C transadmittance type integrator needs three SO-OTAs and one grounded capacitor. The proposed lossy OTA-C transadmittance type integrator shown in Fig. 15 (c) [derived from Fig. 15 (b)] requires one DOOTA, one SO-OTA and one grounded capacitor.

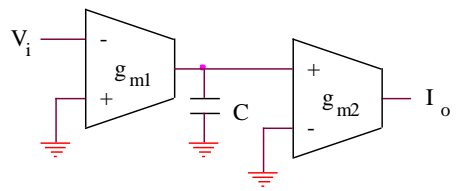

(a)

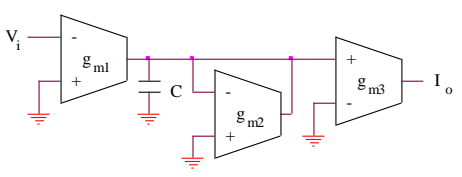

(b)

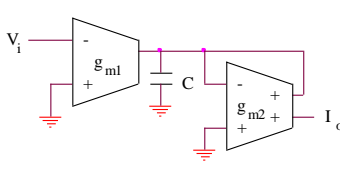

(c)
Fig. 15 Single ended inverting type OTA-C transadmittance-mode (a) lossless integrator, (b) lossy integrator using 3 OTAs, and (c) simplified lossy integrator derived from (b)

The transfer function of single ended OTA-C transadmittance type integrators in Fig. 15 (a)-(c) are respectively shown to be

$$
\frac{\mathrm{I}_{\mathrm{o}}}{\mathrm{V}_{\mathrm{i}}}=-\frac{\mathrm{g}_{\mathrm{m} 1} \cdot \mathrm{g}_{\mathrm{m} 2}}{\mathrm{sC}}
$$

$$
\begin{aligned}
& \frac{\mathrm{I}_{\mathrm{o}}}{\mathrm{V}_{\mathrm{i}}}=-\frac{\mathrm{g}_{\mathrm{m} 1} \cdot \mathrm{g}_{\mathrm{m} 3}}{\left(\mathrm{~g}_{\mathrm{m} 2}+\mathrm{sC}\right)} \\
& \frac{\mathrm{I}_{\mathrm{o}}}{\mathrm{V}_{\mathrm{i}}}=\frac{\mathrm{g}_{\mathrm{m} 1} \cdot \mathrm{g}_{\mathrm{m} 2}}{\left(\mathrm{~g}_{\mathrm{m} 2}+\mathrm{sC}\right)}
\end{aligned}
$$

\section{ACTIVE-RC INTEGRATOR USING FEED FORWARD COMPENSATED OP-AMP}

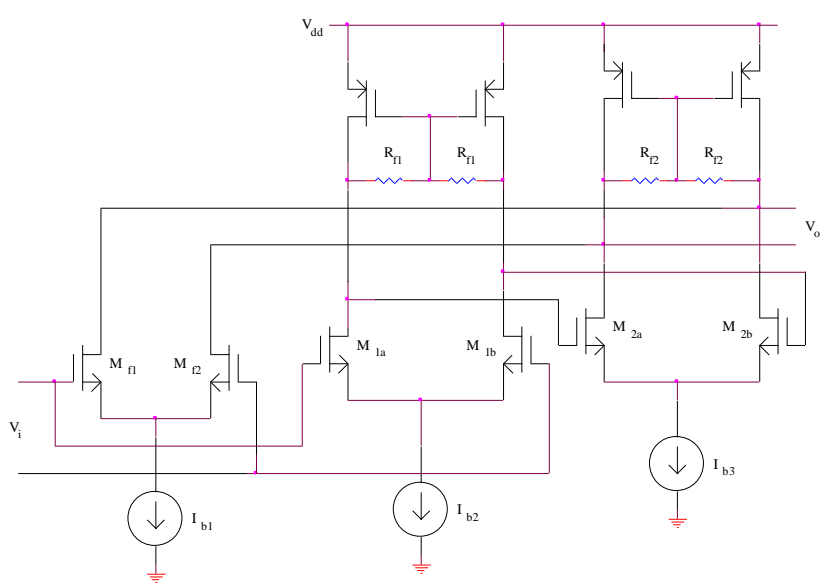

(a)

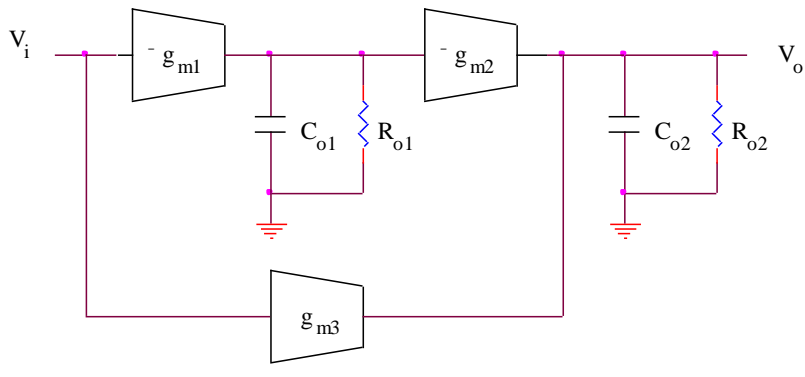

(b)

Fig. 16 (a) Feed-forward compensated opamp schematic and (b) simplified small-signal equivalent circuit of the op-amp

For high-frequency applications, active-RC filters can be derived from opamp-RC filters, by replacing the opamp with a three-OTA-based cell based on feed-forward compensation scheme. These cells use one feed-forward parallel path [31]-[33] and do not need a compensation capacitor. The compensation technique employed in these is known in literature as NCFF (no capacitor feed-forward) technique.

Fig. 16 (a) shows the circuit schematic of the opamp using feed-forward compensation technique, in which $\mathrm{M}_{1 \mathrm{a}, \mathrm{b}}$ and $\mathrm{M}_{2 \mathrm{a}, \mathrm{b}}$ are the transconductors of the first and second stages, while the feed-forward path is composed of $\mathrm{M}_{\mathrm{fl}, 2}$. The $R_{f 1,2}$ are local common-mode feedback (CMFB) resistors. The simplified small-signal equivalent circuit of this op-amp is shown in Fig. 16 (b). The two-stage opamp topology is selected so as to drive resistive loads. The opamp transfer function contains two poles and a LHP zero created by the feed-forward path. The compensation method involves aligning the pole of the second stage and LHP zero as close as possible. This topology ensures 
reduced chip area since the technique does not require large compensation capacitance, when compared to its Miller compensated counterparts.

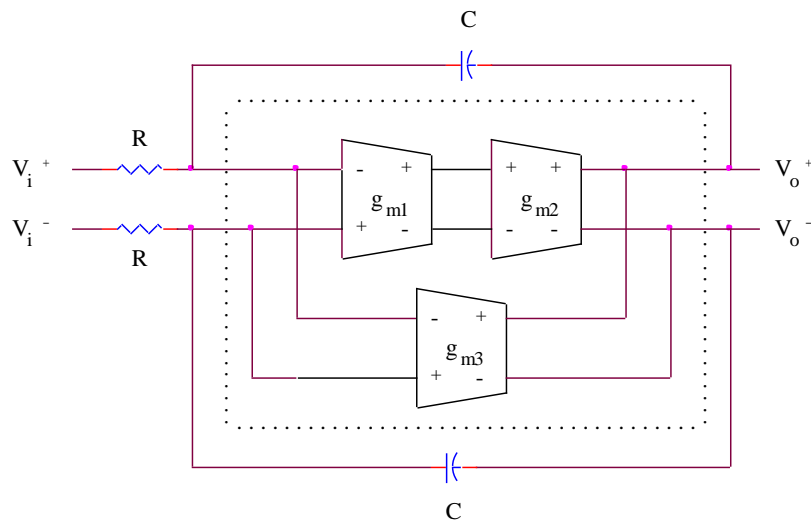

Fig. 17 Active-RC integrator using feed forward compensated opamp

Fig. 17 shows active-RC integrator using feed-forward compensated op-amp [21], [31]-[33], the ideal transfer function of which is shown to be

$$
\frac{V_{o}}{V_{i}}=-\frac{1}{s R C}
$$

\section{SIMULATION RESULTS}

The single ended OTA-C voltage-mode lossless and lossy integrator circuits in Fig. 9 (a)-(b) have been simulated using PSPICE simulator using the design details given in Table I [17]-[27]. The voltage-mode lossless and lossy OTA-C integrator circuits were also simulated using behavioral voltage controlled current source (VCCS) model of OTA (i.e., ideal transconductor with infinite $R_{o}$ and zero $C_{o}$ ) to obtain the ideal characteristics. The schematic circuit of SO-OTA analog block used in the simulation of above mentioned voltage-mode integrator circuits is presented in Fig. 18.

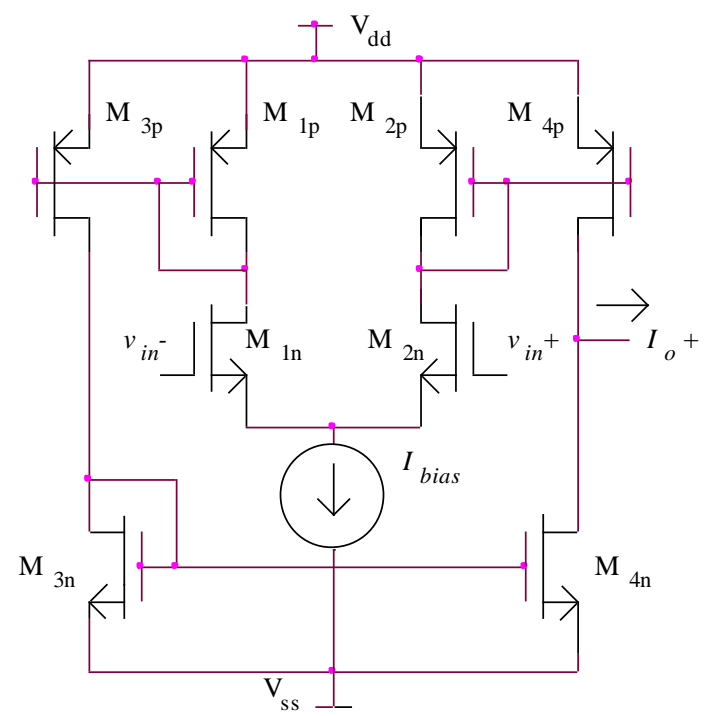

Fig. 18 CMOS schematic circuit of SO-OTA
TABLE I SIMULATION DETAILS

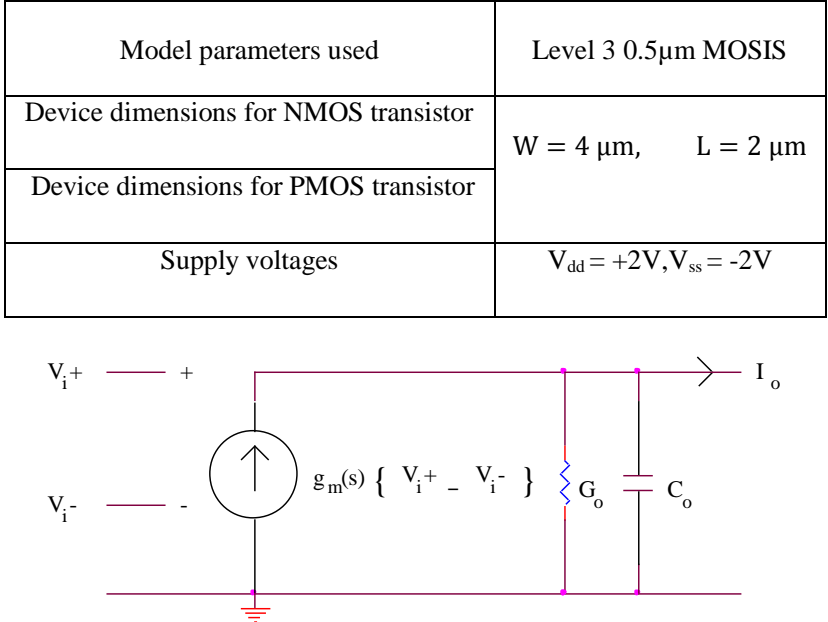

(a)

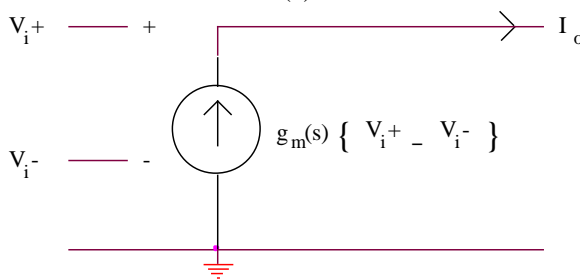

(b)

Fig. 19 (a) Non-ideal and (b) Ideal VCCS model of SO-OTA

The SO-OTA based voltage-mode lossless integrator circuit in Fig. 9 (a) has been simulated using $\mathrm{g}_{\mathrm{m} 1}=$ $53.9 \mu \mathrm{S} \quad\left(\mathrm{I}_{\text {bias } 1}=10 \mu \mathrm{A}\right), \mathrm{C}=8.578 \mathrm{pF}$ designed for unity-gain or pole frequency of $1 \mathrm{MHz}$ and the resulting amplitude and phase responses are shown in Fig. 20 (a)(b).

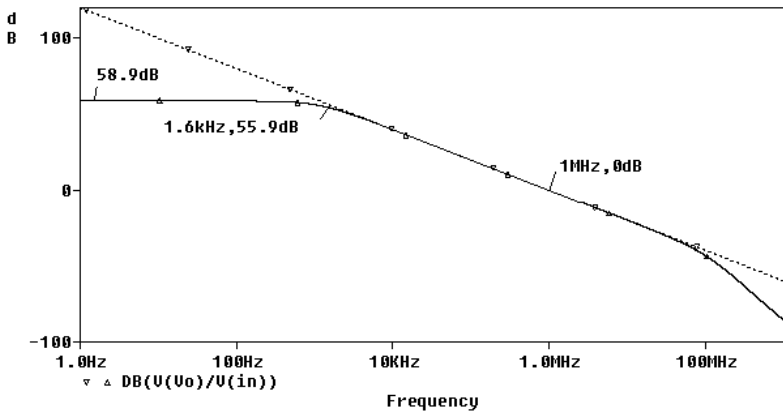

(a)

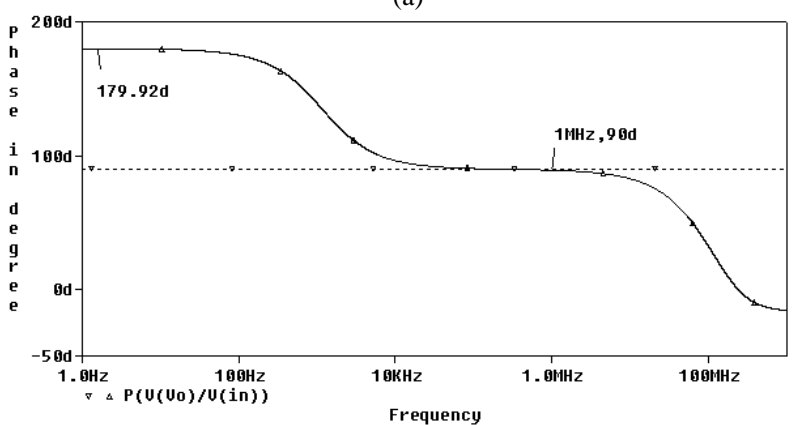

(b)

$\nabla$.... using behavioral OTA, $\Delta \quad$ using Tsukutani OTA

Fig. 20 Amplitude and phase response of single ended OTA-C voltagemode lossless integrator circuit in Fig. 9 (a) 
The voltage-mode lossy OTA-C integrator circuit in Fig. 9 (b) has been simulated using $\mathrm{g}_{\mathrm{m} 1,2}=$ $53.9 \mu \mathrm{S}\left(\mathrm{I}_{\mathrm{bias} 1,2}=10 \mu \mathrm{A}\right), \mathrm{C}=8.578 \mathrm{pF}$ designed for unity dc gain and pole frequency of $1 \mathrm{MHz}$, and the resulting amplitude response is shown in Fig. 21.

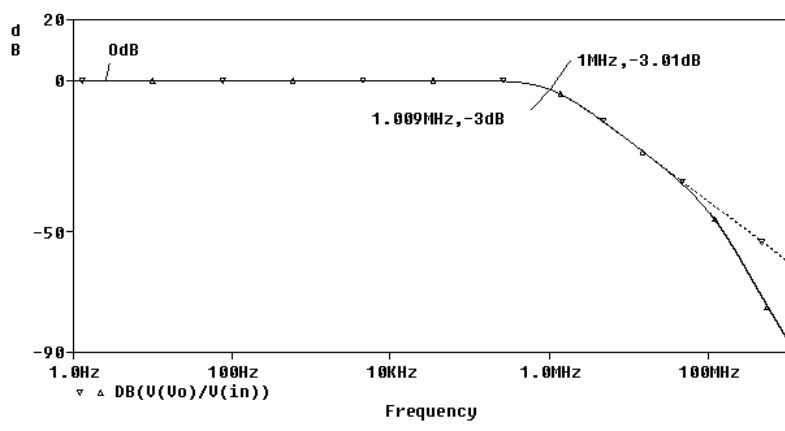

$\nabla \quad \ldots$. using behavioral OTA, $\Delta \ldots$ using Tsukutani OTA

Fig. 21 Amplitude response of single ended OTA-C voltage-mode lossy integrator circuit in Fig. 9 (b)

From the plots presented in Fig. 20 and Fig. 21 it is evident that the simulation results are in good agreement with theory.

\section{CONCLUSION}

In this paper, the circuit realization of inverting and non-inverting types of lossless and lossy integrators using active devices like opamp and OTA has been extensively covered. The voltage-mode, current-mode and transadmittance type integrators using OTA have been discussed. The single ended and fully differential integrator circuits have been discussed thoroughly. The summary of integrators used in various filter structures like Opamp active-RC, active R, Opamp-MOSFET-C, OTA-C-Opamp, OTA-C, active-RC integrator using feed forward compensated op-amp etc. have been discussed. The OTA based integrator circuits have been simulated in PSPICE using a behavioral macro-model of the OTA as well with a practical CMOS OTA circuit. The amplitude and phase response plots obtained for OTA based integrators are in good agreement with theory.

\section{REFERENCES}

[1] S. Sedra and P. O. Brackett, Filter Theory and Design: Active and Passive, Matrix Series in Circuits and Systems, Matrix Publishers, 1978.

[2] R. Schaumann, M. S. Ghausi, K. R. Laker, Design of analog filters: passive, active RC and switched capacitor, Prentice-Hall, Englewood cliffs, New Jersey, 1981.

[3] R. L. Geiger and E. Sanchez-Sinencio, "Active filter design using operational transconductance amplifiers: a tutorial," IEEE Circuit and Devices Magazine, vol. 1, pp. 20-32, 1985

[4] Toumazou, F. D. Lidgey, and D. G. Haigh, Analog IC Design: The Current Mode Approach. London, U.K.: Peregrinus, 1990

[5] T. Deliyannis, Y. Sun, and J. K. Fidler, Continuous-Time Active Filter Design, CRC Press, Florida, U.S.A, 1999.

[6] P. V. Ananda Mohan, Current-Mode VLSI Analog Filters: Design and Applications, Birkhäuser Boston, 2003.

[7] P. V. Ananda Mohan, VLSI Analog Filters: Active RC, OTA-C, and SC, Birkhäuser Boston, 2013
8] Kerwin, William J. ; Huelsman, L.P. ; Newcomb, R.W., "StateVariable Synthesis for Insensitive Integrated Circuit Transfer Functions," IEEE Journal of Solid-State Circuits, vol. 2, no. 3, pp. 87 - 92, Sep 1967

[9] Thomas, Lee C., "The biquad: Part I-Some practical design considerations," IEEE Transactions on Circuit Theory, vol. 18, no. 3 , pp. 350-357, 1971

[10] Thomas, Lee C., "The biquad: part II--a multipurpose active filtering system," IEEE Transactions on Circuit Theory, vol. 18, no. 3, pp. 358-361, 1971

[11] Åkerberg, Dag, and Kare Mossberg, "A versatile active RC building block with inherent compensation for the finite bandwidth of the amplifier," IEEE Transactions on Circuits and Systems, vol. 21, no. 1 pp. 75-78, 1974

[12] M. Banu and Y. Tsividis, "Fully integrated Active RC filters in MOS technology," IEEE Journal of Solid-State Circuits, vol. 18, no. 6, pp. 644-651, 1983.

[13] A. M. Soliman, M. Fawzy, "A universal active R biquad," International Journal of Circuit Theory and Applications, vol. 6, no. 2, pp. 153-157, 1978

[14]P. V. Ananda Mohan, "Novel active filters using amplifier pole," Electronics Letters, vol. 16, no. 10, pp. 378-380, 1980.

[15] J. R. Brand, R. Schaumann, "Active R filters: review of theory and practice," IEE Journal on Electronic Circuits and Systems, vol. 2, no. 4 , pp. 89-101, 1978

[16] M. Al-Hashimi, "Current mode filter structure based on dual output transconductance amplifiers," Electronics Letters, vol. 32, pp. 25-26, 1996.

[17] T. Tsukutani, Y. Sumi, and Y. Fukui, "Electronically tunable current-mode OTA-C biquad using two-integrator loop structure," Frequenz, vol. 60, pp. 53-56, 2006

[18] Dattaguru V. Kamat, P.V. Ananda Mohan and K. Gopalakrishna Prabhu, "Novel First-order and Second-Order Current-mode filters using dual-output OTAs and Grounded Capacitors," IEEE Asia Pacific Region 10 (TENCON) Conference held at Hyderabad, India, IEEExplorer, pp. 1-6, 19-21Nov. 2008.

[19] Dattaguru V. Kamath, P. V. Anandamohan and K. Gopalkrishna Prabhu, "Novel first order and second order current-mode filters using multiple output operational transconsuctance amplifiers," Circuits, Systems, and Signal Processing, Birkhäuser Boston Publishers, vol. 29, no. 3, pp. 553-576, June 2010.

[20] Dattaguru V. Kamat, P. V. Ananda Mohan and K. Gopalakrishna Prabhu, "Current-mode operational transconductance amplifiercapacitor biquad filter structures based on Tarmy-Ghausi Active-RC filter and second-order digital all-pass filters," IET Circuits, Devices and Systems, vol. 4, no. 4, pp. 346-364, July 2010.

[21] Dattaguru V. Kamat, P. V. Ananda Mohan and K. Gopalakrishna Prabhu, "Active-RC filters using two-stage OTAs with and withou feed-forward compensation," IET Circuits, Devices and Systems, vol. 5 , no. 6 , pp. 527-535, Nov 2011.

22] Dattaguru. V. Kamath P. V. Ananda Mohan Gopalakrishna Prabhu K, "OTA-based current-mode filter and oscillator," US Patent, No. US 8,659,363 B2, Feb 2014

[23] Dattaguru V. Kamath, "New OTA-C Current-Mode Second-Order Filters," IIE International Conference on Innovative Engineering Technologies (ICIET 2014) held at Bangkok, Thailand, pp. 137-143, 28-29 Dec. 2014

[24] Dattaguru V. Kamath, "TO-OTA based current-mode biquad filters," Transactions on Engineering and Sciences, vol. 2, no. 8, pp. 15-26, August 2014.

[25] Dattaguru V. Kamath, "Novel OTA-C Current-Mode Third-Order Band-Pass Filters," International Journal of Innovative Research in Electrical, Electronics, Instrumentation and Control Engineering (IJIREEICE), vol. 2, no. 8, pp. 1861 - 1865, August 2014.

[26] Dattaguru. V. Kamath, "New OTA-C Current-Mode Second-order and Fourth-Order Band-Pass Filters," International Journal of Innovative Research in Electrical, Electronics, Instrumentation and Control Engineering (IJIREEICE), vol. 3, no. 6, pp. 130-134, June 2015.

[27] Dattaguru. V. Kamath, "OTA-C Transimpedance Biquads derived from Passive Filters," International Journal of Technical Research and Applications (IJTRA), Special Issue 23, pp. 6-12, June, 2015.

[28] Ibrahim, Muhammed A., and Hakan Kuntman. "A Novel Transadmittance-Type KHN-Biquad Employing DO-OTA with Only Two Grounded Capacitors," WSEAS Transactions on Circuits and Systems, vol. 2, pp. 400-403, 2003. 
[29] D. R. Bhaskar, A. K. Singh, R. K. Sharma and R. Senani, "New OTA-C universal current-mode/ transadmittance biquads," IEICE Electronics Express, vol. 2, no. 1, pp. 8-13, 2005.

[30] Hua-Pin Chen, Yi-Zhen Liao, Wen-Ta Lee, "Tunable mixed-mode OTA-C universal filter," Analog Integrated Circuits and Signal Processing, vol. 58, no. 2, pp. 135-141, 2009.

[31] B. Thandri, J. Silva-Martinez and F. Maloberti, "A feedforward compensation scheme for high gain wideband amplifiers," Proceedings of the $8^{\text {th }}$ IEEE International Conference on Electronics, Circuits and Systems, vol. 3, pp. 1115-1118, 2001.

[32] B. K. Thandri and J. Silva-Martinez, "A robust feedforward compensation scheme for multistage operational transconductance amplifiers with no Miller capacitors," IEEE Journal of Solid-State Circuits, vol. 38, no. 2, pp. 237-243, 2003.

[33] S. Szczepanski and S. Koziel, "Phase compensation scheme for feed-forward linearized CMOS operational transconductance amplifier," Bulletin of the Polish Academy of Sciences, Technical Sciences, vol. 52, no.2, pp. 141-148, 2004.

\section{BIOGRAPHY}

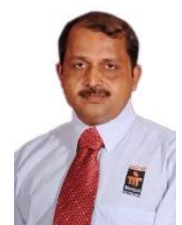

Dr. D. V. Kamath obtained $\mathrm{PhD}$ in the field of Analog VLSI Signal Processing from Manipal University (MU), Manipal, India in the year 2013. He obtained B.E (Electronics and Communication) and M.E (Digital electronics) from B. V. Bhoomreddi College of Engineering and Technology, Karnataka

University, Dharwad in the year 1987 and 1997 respectively. Currently working as Professor in the Department of Electronics and Communication Engineering, Manipal Institute of
Technology, Manipal University, Manipal, India. The research and academic contribution includes grant of one US patent, 20 full regular papers published in indexed international journals of good repute, 5 indexed international conference publications. Author's areas of research interest include Digital, Analog and Mixed Signal VLSI design and Analog VLSI Signal Processing

He has presented/ conducted key-note address/ tutorials and seminars at various International/ National Level Conferences/ Workshops. Author's Biography/ Profile is published in the 2011-2012 (11th) Edition of Marquis Who's Who in Science and Engineering and 2014 (31st) and 2015 (32 $\left.{ }^{\text {nd }}\right)$ Edition of Marquis Who's Who in the World, the world-renowned reference directories. He is been working as Editor of Transactions on Engineering and Sciences (TES) Journal and Advisory Board Member of International Journal of Innovative Research in Electrical, Electronics, Instrumentation and Control Engineering (IJIREEICE), International Journal of Advanced Research in Computer and Communication Engineering (IJARCCE), Journal of Global Research in Electronics and Communication (JGREC). He is currently working as Reviewer for Adavances in Signal Processing Journal. He has reviewed research papers for various international/ national level conferences 